\title{
Pathology of endometrium treated with tamoxifen
}

\author{
S M Ismail
}

Abstract

Aims-To determine the type of endometrial abnormalities associated with prolonged tamoxifen treatment and to investigate the correlation between tamoxifen dose and any abnormalities detected.

Methods-Endometria from 19 prospectively collected breast cancer patients treated with tamoxifen were ascribed a pathological diagnosis and the findings compared with those in a control group matched for age and presentation. The abnormalities were related to cumulative tamoxifen dose.

Results-The two asymptomatic treated patients had generalised simple endometrial hyperplasia at necropsy. No endometrial abnormalities were seen at necropsy in the two control cases. Of the 17 patients treated with tamoxifen who underwent surgery for gynaecological symptoms, 11 had hyperplastic endometrial polyps characterised by epithelial metaplasias and patchy periglandular condensation of stroma. Two women had primary endometrial malignancies with myometrial invasion, and three women, one of whom had previously presented with a benign polyp, had an endometrial polyp-cancer on a background of hyperplasia. Endometrial malignancies were confined to women who had taken more than $35 \mathrm{~g}$ of tamoxifen. The control group included no endometrial polyp-cancers, only one patient with an endometrial polyp, four women with endometrial hyperplasia and four with primary endometrial malignancy.

Conclusions-These findings support a link between prolonged tamoxifen treatment and endometrial malignancy and identify a subgroup of patients-that is, those who have taken more than $35 \mathrm{~g}$ of tamoxifen, who may be at increased risk of endometrial cancer. The spectrum of pathological findings in patients treated with tamoxifen suggests that the drug promotes endometrial growth and that endometrial polyps may be an important intermediate step in endometrial carcinogenesis.

(F Clin Pathol 1994;47:827-833) Figure 1 Postmortem
uterus of an 85 year old woman treated with tamoxifen. The uterus is enlarged and shows diffuse endometrial thickening with numerous cystic spaces.

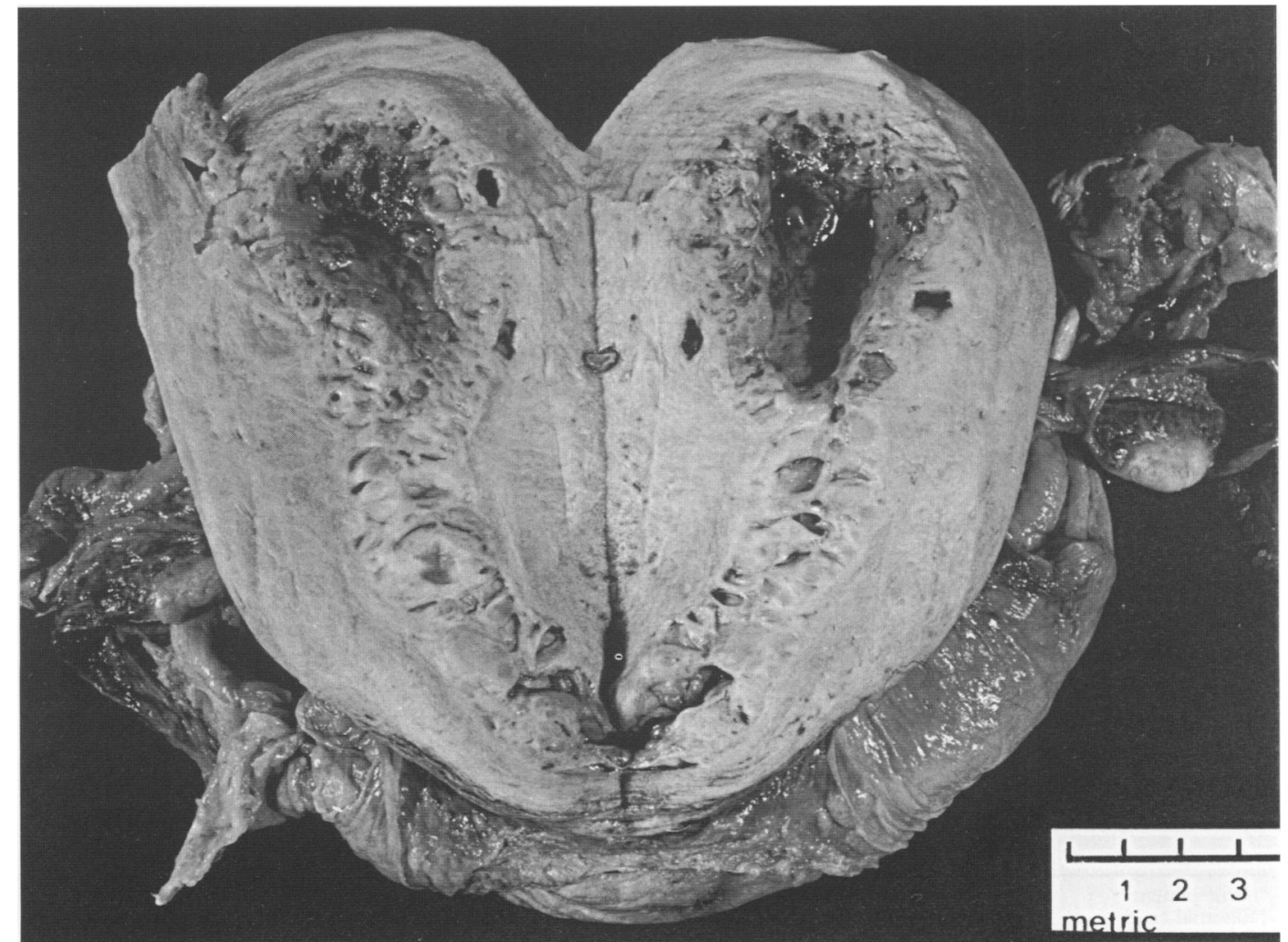


Tamoxifen is a non-steroidal triphenylethylene derivative with predominant anti-oestrogen activity. ${ }^{1}$ It has long been in widespread use in the management of established breast carcinoma. Perceived as safe, effective, and with negligible side effects, ${ }^{2}$ it has recently been advocated as of potential value in breast cancer prevention ${ }^{3}$ and its efficacy as a preventive agent is currently being evaluated in asymptomatic women deemed to be at increased risk of breast cancer. ${ }^{4}$

Although an oestrogen antagonist in the breast, tamoxifen is structurally closely related to the synthetic oestrogen diethylstilbestrol ${ }^{1}$ and is known to have oestrogen agonist activity in the vaginal epithelium ${ }^{5-7}$ and endo- metrium $^{89}$ of postmenopausal women. In keeping with such an effect, recent studies have reported an increased incidence of endometrial carcinoma, ${ }^{10}$ polyps, ${ }^{911}$ and hyperplasia $^{911}$ in women treated with tamoxifen. However, existing publications on the pathology of endometrium in women treated with the drug are few and far between, ${ }^{12-14}$ and the association between tamoxifen dose and endometrial disease has not been studied. This study investigates the relation between tamoxifen dose and the endometrial abnormalities detected in a group of breast cancer patients who received prolonged tamoxifen treatment.

Figure 2 A benign endometrial polyp in a 54 year old woman treated with tamoxifen who underwent hysterectomy for postmenopausal bleeding.

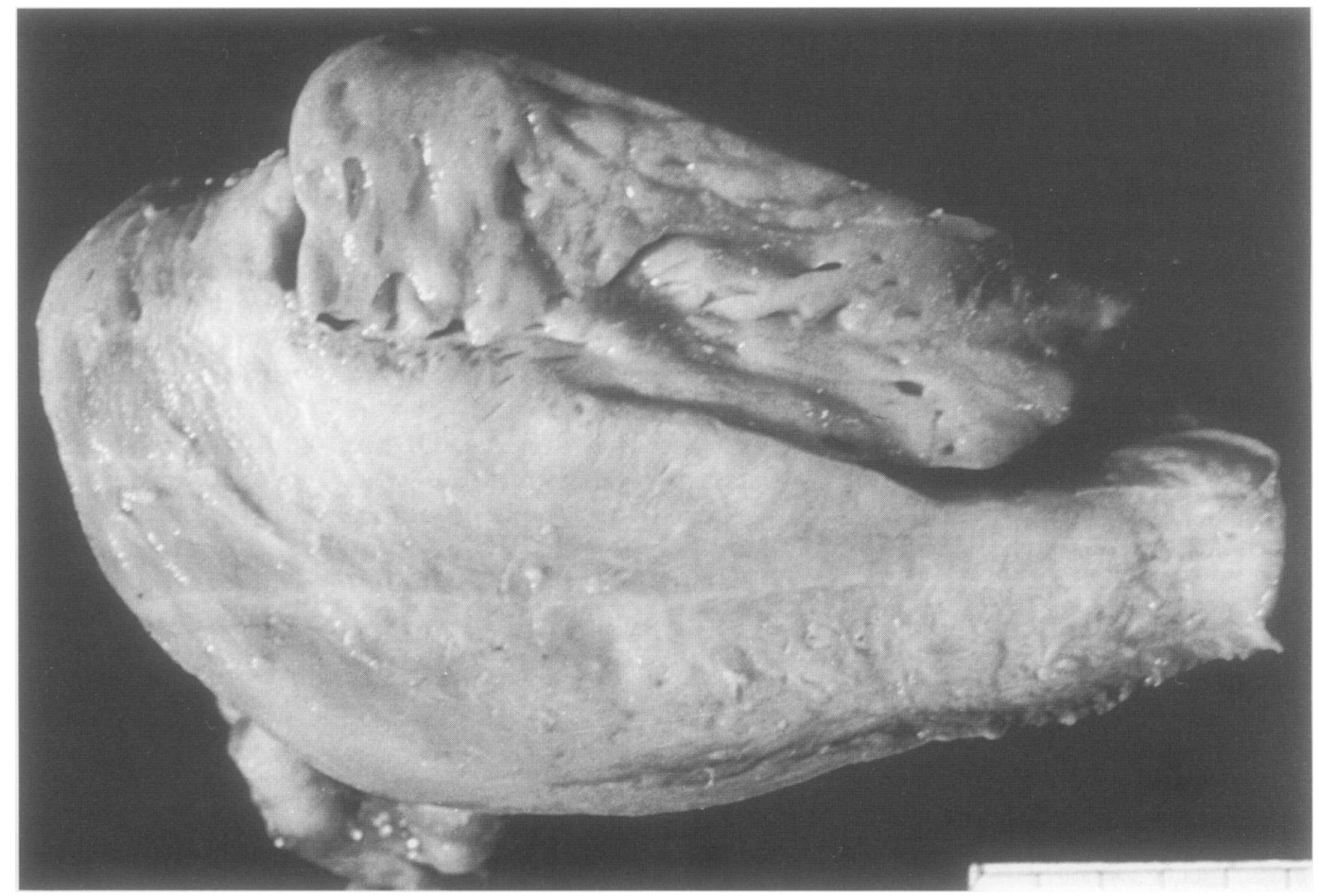

Clinical presentation and pathological findings in women treated with tamoxifen compared with untreated controls

\begin{tabular}{|c|c|c|c|c|}
\hline Case No & Symptoms & Age & Endometrial pathology & Control pathology \\
\hline $\begin{array}{l}1 \\
2 \\
3\end{array}$ & $\begin{array}{l}\text { PMB } \\
\text { PMB } \\
\text { PMB }\end{array}$ & $\begin{array}{l}54 \\
52 \\
54\end{array}$ & $\begin{array}{l}\text { Benign polyp }(3 \mathrm{~cm}) \text {; background simple endometrial hyperplasia } \\
\text { Benign polyp }(3.3 \mathrm{~cm}) \text {; background cystic atrophy } \\
\text { Benign polyp }(8 \mathrm{~cm}) \text {, focus of secondary carcinoma within polyp and } \\
\text { background simple endometrial hyperplasia }\end{array}$ & $\begin{array}{l}\text { Endometrial hyperplasia } \\
\text { Endometrial carcinoma } \\
\text { Endometrial polyp }\end{array}$ \\
\hline $\begin{array}{l}4 \\
5^{\star} \\
6 \\
7 \\
8+ \\
9 \dagger\end{array}$ & $\begin{array}{l}\text { Menorrhagia } \\
\text { PMB } \\
\text { PMB } \\
\text { PMB } \\
\text { Clear discharge } \\
\text { PMB }\end{array}$ & $\begin{array}{l}54 \\
74 \\
59 \\
52 \\
59 \\
67\end{array}$ & $\begin{array}{l}\text { Two benign polyps }(5 \mathrm{~cm} \text { and } 1.5 \mathrm{~cm}) ; \text { background cystic atrophy } \\
\text { Benign polyp }(4 \mathrm{~cm}) ; \text { no background endometrium } \\
\text { Benign polyp }(2.3 \mathrm{~cm}) ; \text { no background aendometrium } \\
\text { Benign polyp }(1.5 \mathrm{~cm}) ; \text { no background endometrium } \\
\text { Benign polyp }(5 \mathrm{~cm}) \text { and background simple endometrial hyperplasia } \\
\text { Benign polyp }(6 \mathrm{~cm}) \text {, three previous polyps, and background simple endometrial } \\
\text { hyperplasia }\end{array}$ & $\begin{array}{l}\text { No endometrial abnormality } \\
\text { Endometrial carcinoma } \\
\text { No endometrial abnormality } \\
\text { Endometrial hyperplasia } \\
\text { No endometrial abnormality } \\
\text { Endometrial hyperplasia ?polyp }\end{array}$ \\
\hline $\begin{array}{l}10 \\
11\end{array}$ & $\begin{array}{l}\text { PMB } \\
\text { PMB }\end{array}$ & $\begin{array}{l}58 \\
81\end{array}$ & $\begin{array}{l}\text { Two benign polyps }(8 \mathrm{~cm} \text { and } 3 \mathrm{~cm}) \text {, and background simple endometrial hyperplasia } \\
\text { Three benign polyps }(16 \mathrm{~cm}, 4 \mathrm{~cm} \text { and } 4 \mathrm{~cm}) \text { and background simple hyperplasia } \\
\text { and progestogen changes }\end{array}$ & $\begin{array}{l}\text { No endometrial abnormality } \\
\text { Malignant mixed Müllerian } \\
\text { tumour }\end{array}$ \\
\hline $\begin{array}{l}12 \\
13 \\
14 \\
15 \\
16\end{array}$ & $\begin{array}{l}\text { Menorrhagia } \\
\text { Menorrhagia } \\
\text { Necropsy } \\
\text { Necropsy } \\
\text { PMB }\end{array}$ & $\begin{array}{l}47 \\
49 \\
85 \\
91 \\
58\end{array}$ & $\begin{array}{l}\text { Progestogen changes only } \\
\text { Progestogen changes only } \\
\text { Simple endometrial hyperplasia } \\
\text { Simple endometrial hyperplasia } \\
\text { Adenocarcinoma with focal sarcomatous differentiation and extensive } \\
\text { myometrial infiltration }\end{array}$ & $\begin{array}{l}\text { No endometrial abnormality } \\
\text { No endometrial abnormality } \\
\text { No endometrial abnormality } \\
\text { No endometrial abnormality } \\
\text { Endometrial hyperplasia }\end{array}$ \\
\hline $\begin{array}{l}17 \\
18\end{array}$ & $\begin{array}{l}\text { Menorrhagia } \\
\text { PMB }\end{array}$ & $\begin{array}{l}49 \\
70\end{array}$ & $\begin{array}{l}\text { Invasive well differentiated adenocarcinoma with extensive mayometrial invasion } \\
\text { Background simple endometrial hyperplasia, multiple hyperplastic polyps with } \\
\text { varying degrees of cytological atypia, and a polypoid superficial carcinoma }\end{array}$ & $\begin{array}{l}\text { No endometrial abnormality } \\
\text { No endometrial abnormality }\end{array}$ \\
\hline $19 \dagger$ & PMB & 62 & $\begin{array}{l}\text { Background simple endometrial hyperplasia and multiple benign polyps with foci } \\
\text { of superficial carcinoma }\end{array}$ & Endometrial carcinoma \\
\hline $20 \star$ & Necropsy & 76 & $\begin{array}{l}\text { Background hyperplasia with focal atypia and benign polyp with microscopic focus } \\
\text { of adenocarcinoma }\end{array}$ & \\
\hline
\end{tabular}



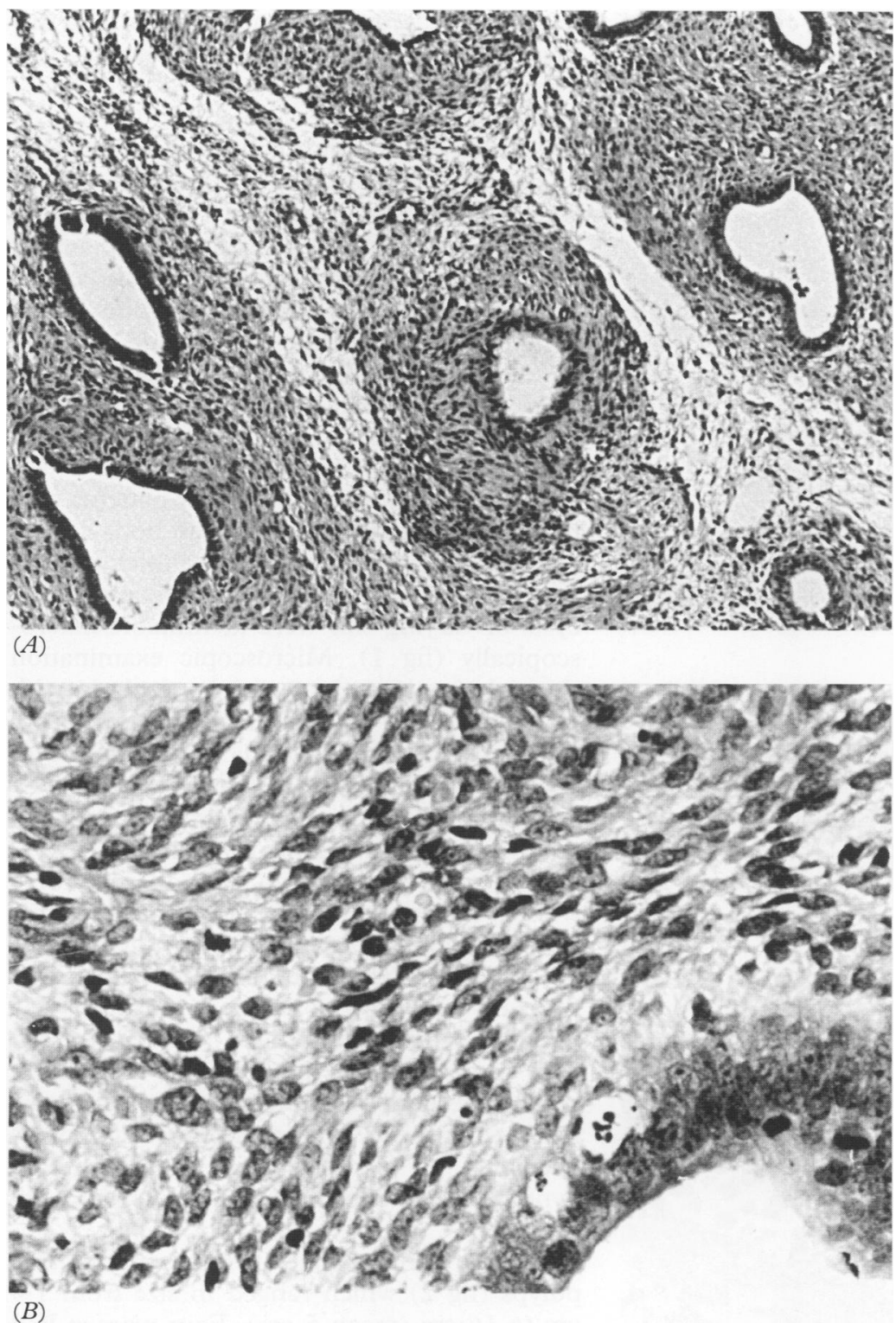

Figure 3 Microscopically, tamoxifen-associated benign endometrial polyps were characterised by a combination of $(A)$ focal periglandular condensation of stromal cells, (B) mitotic activity in epithelial and stromal cells, and a range of epithelial metaplasias (haematoxylin and eosin).

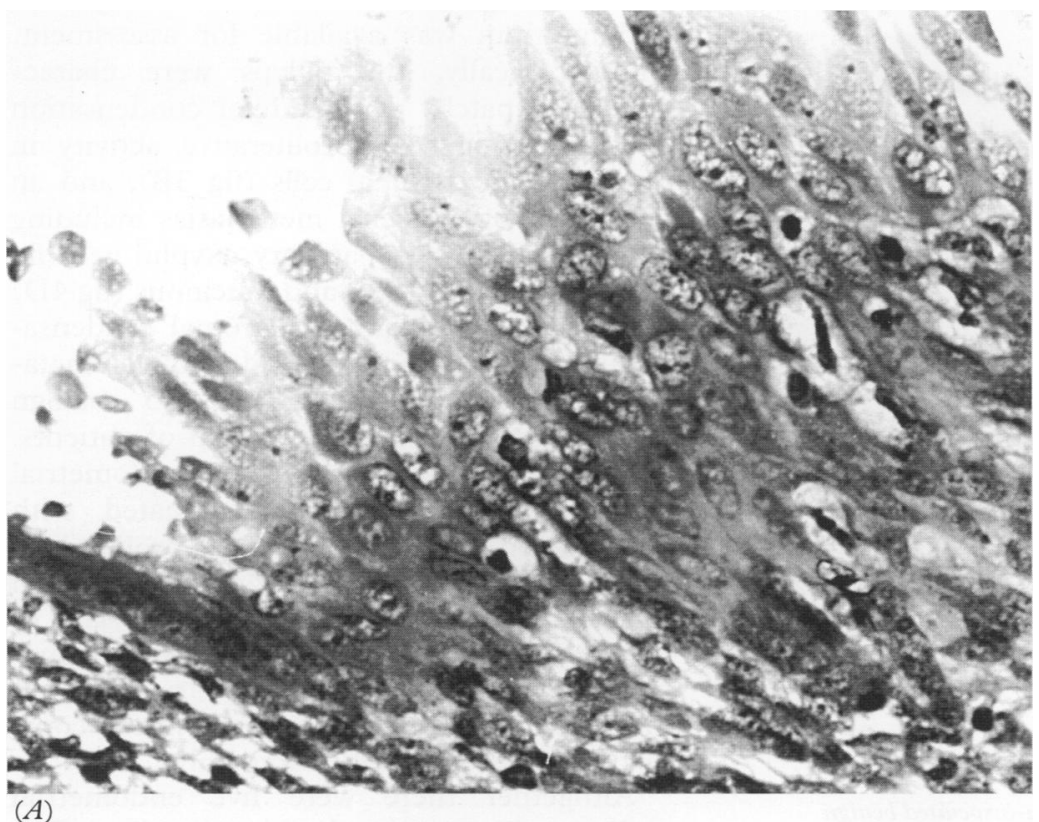

Figure 4 The range of epithelial metaplasias seen in tamoxifen-associated benign endometrial polyps included $(A)$ squamoid metaplasia.

\section{Methods}

The study population comprised 19 breast cancer patients treated with tamoxifen. The data were collected prospectively between 1987 and 1992. It includes two necropsies, 14 women who underwent surgery at the University Hospital of Wales for tamoxifenassociated gynaecological symptoms, and three patients treated at other hospitals in the area.

The two necropsy patients, aged 85 and 92 , had died of myocardial infarction and lobar pneumonia, respectively. Neither was known to have had any gynaecological symptoms and there was no history in either woman of any other hormone treatment.

The symptomatic patients ranged in age from 47 to 81 years (mean 58.5 years) and presented with prolonged irregular perimenopausal bleeding $(n=4)$, post menopausal bleeding $(n=12)$, or vaginal discharge $(n=1)$. Treatment consisted of either polypectomy $(n=5)$ or hysterectomy $(n=$ 12). Three patients had received progestogens for menorrhagia but none had received any other form of endocrine treatment.

The specimens were fixed in $10 \%$ buffered formalin and routinely processed. Every specimen was ascribed a pathological diagnosis following examination of the haematoxylin and eosin stained sections and before tamoxifen dose was known. Information about daily tamoxifen dose and duration of treatment was obtained from the case notes. The cumulative dose of tamoxifen was calculated from the daily dose of the drug and the duration of treatment, taking into account recorded alterations in daily dose and assuming that there are 30 days per calendar month.

A control group, matched as closely as possible to the study group for age at presentation, was selected for comparison. The mean age of the control patients was 60.8 years while the mean age of the test group was $61 \cdot 8$ years.

Two postmenopausal breast cancer patients who had received no tamoxifen or any other endocrine treatment, had had no gynaecological symptoms, and who had died over the study period were selected as controls for the two asymptomatic test cases.

The symptomatic group of study patients was compared with a control group of agematched women presenting with identical symptoms over the last two years of the study. None of the patients in this control group had breast cancer and none had received tamoxifen, hormone replacement therapy, or any other endocrine treatment which might have affected endometrial morphology.

\section{Results}

The results are summarised in the table. One test patient (case 5) features twice, having had a benign endometrial polyp after 16 months of tamoxifen treatment and a superficial endometrial carcinoma in a second endome- 

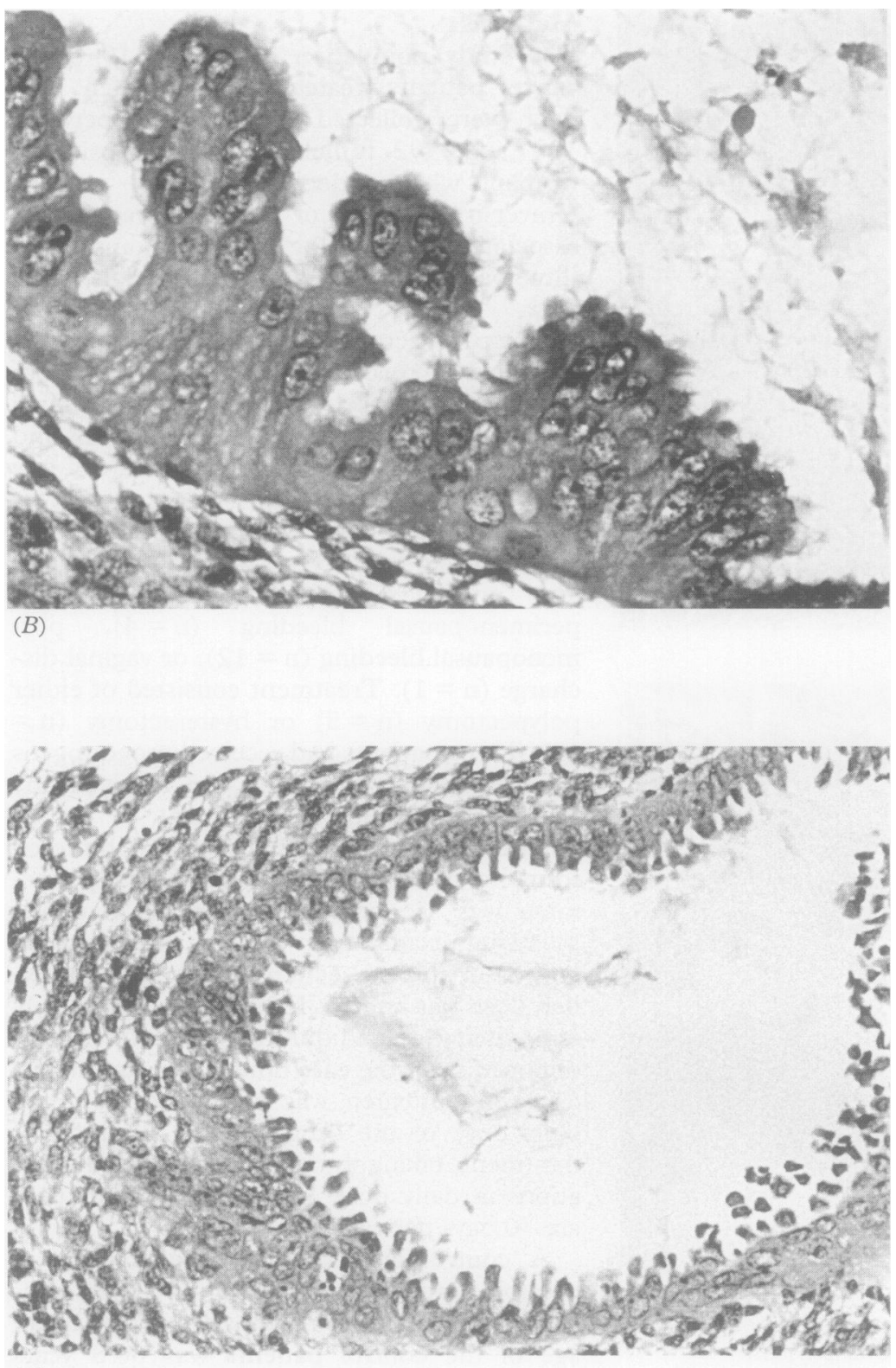

(C)

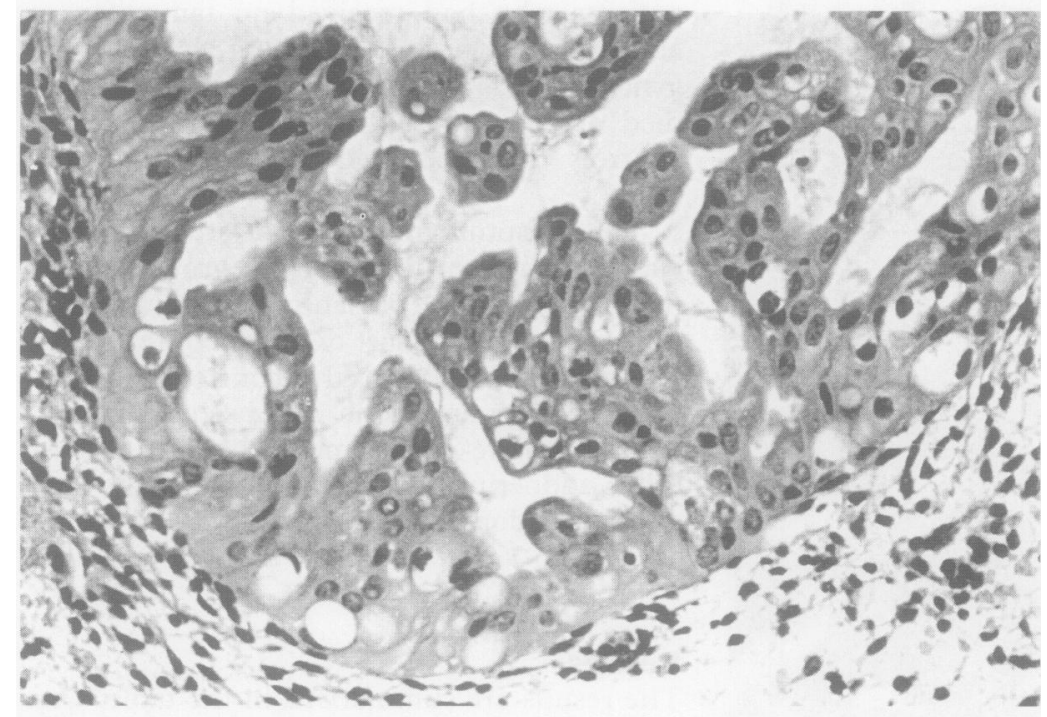

(D)

Figure 4 The range of epithelial metaplasias seen in tamoxifen-associated benign endometrial polyps included (B) papillary oxyphil cell metablasia, (C) apocrine metaplasia and (D) mucinous metaplasia (haematoxylin aind eosin). trial polyp, discovered at necropsy, after a further 30 months of tamoxifen treatment.

\section{CONTROL GROUP}

No endometrial abnormalities were detected at necropsy in the two uteri from the breast cancer patients who had not received tamoxifen. Of the remaining 17 control patients, four had endometrial hyperplasia, three had primary endometrial carcinoma, one had a malignant mixed Müllerian tumour, one had an endometrial polyp, and eight had no clinically relevant endometrial abnormalities.

\section{STUDY GROUP}

The two asymptomatic necropsy patients who had been treated with tamoxifen both had an enlarged uterus with generalised thickening of the endometrium within which numerous cysts of varying size were identifiable macroscopically (fig 1). Microscopic examination showed simple endometrial hyperplasia with cystic dilatation of endometrial glands and a fibrotic endometrial stroma. No evidence of atypical hyperplasia or malignancy was seen.

A range of endometrial findings was seen in the symptomatic patients treated with tamoxifen. Endometria from two of the three women treated with progestogen showed stromal decidualisation with no other major pathological findings; both these women had received very low doses of tamoxifen. The remaining 15 symptomatic women treated with tamoxifen had pathological abnormalities of the endometrium which fell into two main categories: benign endometrial polyps occurring on a background of endometrial hyperplasia; and primary endometrial malignancies.

Eleven patients had benign endometrial polyps (fig 2) which ranged in size from 1.5 $\mathrm{cm}$ to $16 \mathrm{~cm}$ (mean $5 \mathrm{~cm}$ ). Four women had multiple polyps either synchronously or metachronously. The polyps occurred on a background of simple endometrial hyperplasia in six of eight instances where background endometrium was available for assessment. Microscopically, the polyps were characterised by patchy periglandular condensation of stroma (fig 3A), proliferative activity in epithelial and stromal cells (fig 3B), and an admixture of epithelial metaplasias including squamoid (fig 4A), papillary oxyphil cell (fig 4B), apocrine (fig 4C), and mucinous (fig 4D) metaplasias. Periglandular stromal condensation, proliferative activity, and epithelial metaplasias coexisted in 12 of 15 benign endometrial polyps in this group of patients. The remaining three benign endometrial polyps, all from a patient treated with progestogen (case 11) lacked proliferative activity but did show periglandular stromal condensation and epithelial metaplasias. In contrast, a consecutive series of 40 endometrial polyps of the usual type revealed no instances in which these three microscopic features coexisted in the same polyp.

Altogether there were five endometrial malignancies associated with tamoxifen. One of these was an adenocarcinoma of the 


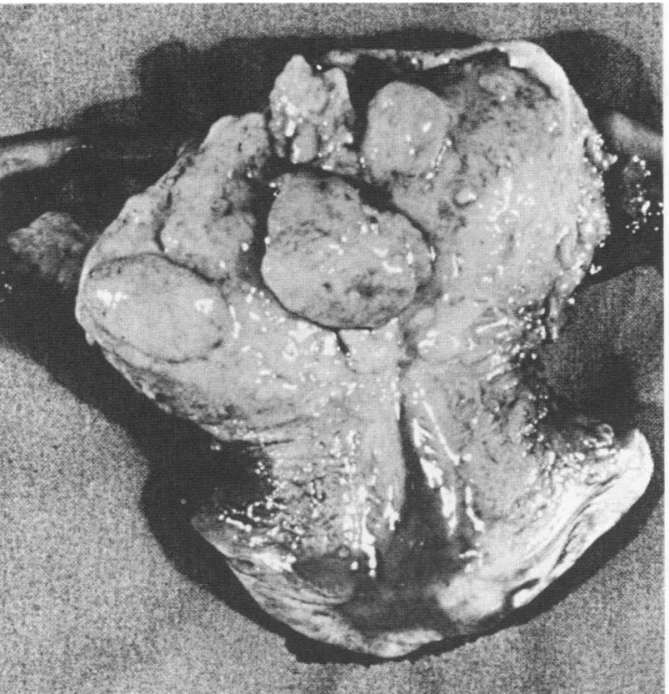

(A)

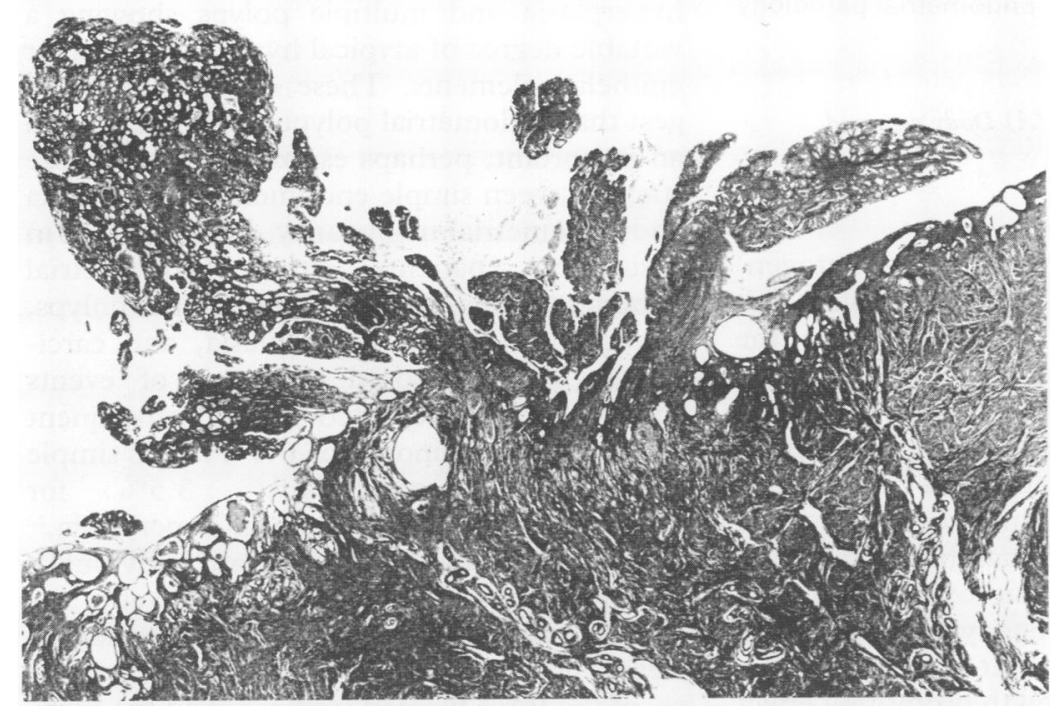

(B)

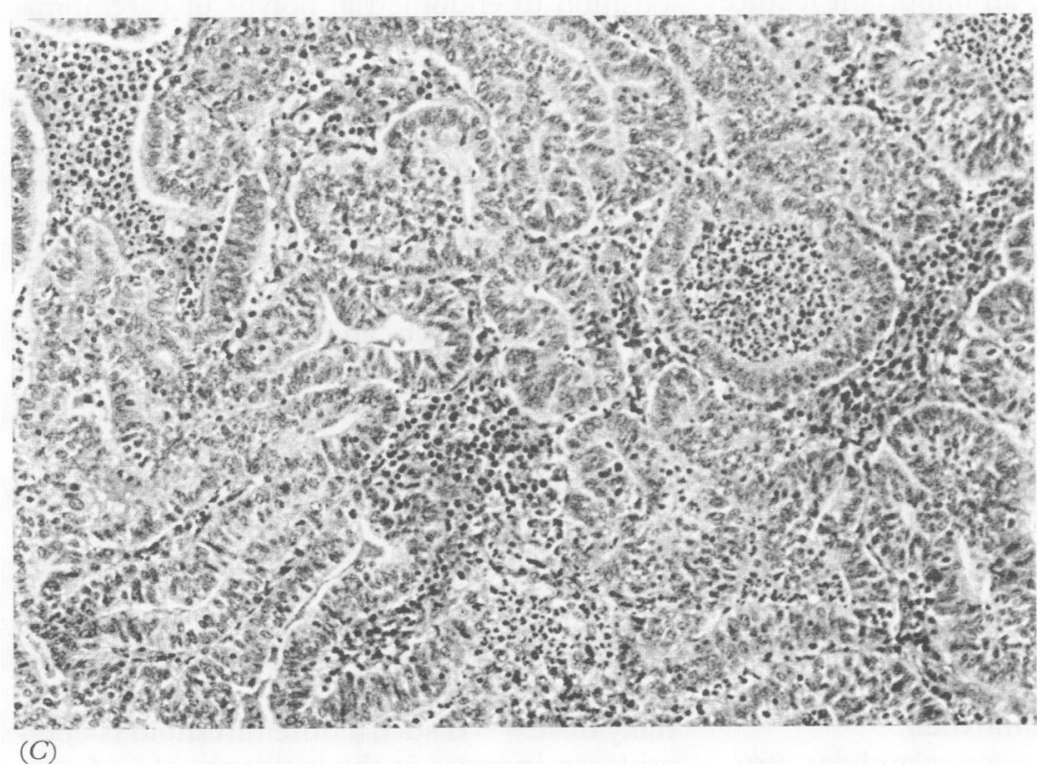

Figure 5 (A) Multiple endometrial polyps in a 70 year old woman treated with tamoxifen who underwent hysterectomy for postmenopausal bleeding. (B) On microscopic examination, there was background endometrial hyperplasia and one polyp contained (C) a superficial endometrial carcinoma (haematoxylin and eosin). endometrium with sarcomatous areas (carcinosarcoma) and another a well differentiated endometrial carcinoma; in both, the tumour showed extensive myometrial infiltration. In three additional cases a superficial endometrial carcinoma (fig 5) confined to the endometrium occurred within an endometrial polyp. The background endometrium in these uteri with superficial endometrial carcinoma showed cystic hyperplasia with benign polyps (fig 5). The background benign polyps in these cases were characterised by hyperplasia with varying degrees of cytological atypia as well as focal periglandular stromal condensation and epithelial metaplasias.

Figure 6 summarises the correlation between endometrial pathology, tamoxifen dose, and duration of treatment. The patient (case 5), who initially presented with postmenopausal bleeding from an endometrial polyp and who subsequently was found to have an endometrial polyp-cancer at necropsy, features twice in this figure. Primary endometrial malignancy occurred in patients treated either with $20 \mathrm{mg}$ or $40 \mathrm{mg}$ tamoxifen daily. However, the tumours in the former group developed after a longer period of treatment than those occurring in patients treated with the higher daily dose. All five primary endometrial malignancies occurred in women who had taken a cumulative tamoxifen dose of more than $35 \mathrm{~g}$. Of the remaining six women who had received tamoxifen in excess of this threshold dose, four had benign endometrial polyps and two had generalised endometrial hyperplasia.

\section{Discussion}

This study has revealed a spectrum of proliferative abnormalities among women treated with tamoxifen, comprising generalised simple endometrial hyperplasia in the two asymptomatic patients and hyperplasia with polyps, polyp-cancers, or primary invasive malignancies in the symptomatic patients. The control group of women showed a much lower incidence of endometrial polyps, no endometrial polyp-cancers, and a higher incidence of "no endometrial abnormality".

It is at first sight surprising to find proliferative endometrial abnormalities in women treated with tamoxifen as the drug, used for its oestrogen antagonist effects in breast carcinoma, might be expected to exert similar effects on the endometrium with consequent inhibition of endometrial growth. However, tamoxifen exerts a well documented oestrogen-like effect on cervico-vaginal squamous epithelial differentiation in postmenopausal women. ${ }^{5-7}$ Previous observations, ${ }^{811} 13$ which suggested a similar oestrogen-like effect on the postmenopausal endometrium, have been supported by a recent study ${ }^{9}$ which found that breast cancer patients treated with the drug had a thicker endometrium than untreated controls, on transvaginal sonography, and a lower incidence of atrophic endometrium on hysteroscopy. The occurrence, in the present study, of proliferative endometrial abnormalities in all but two treated women (both of 


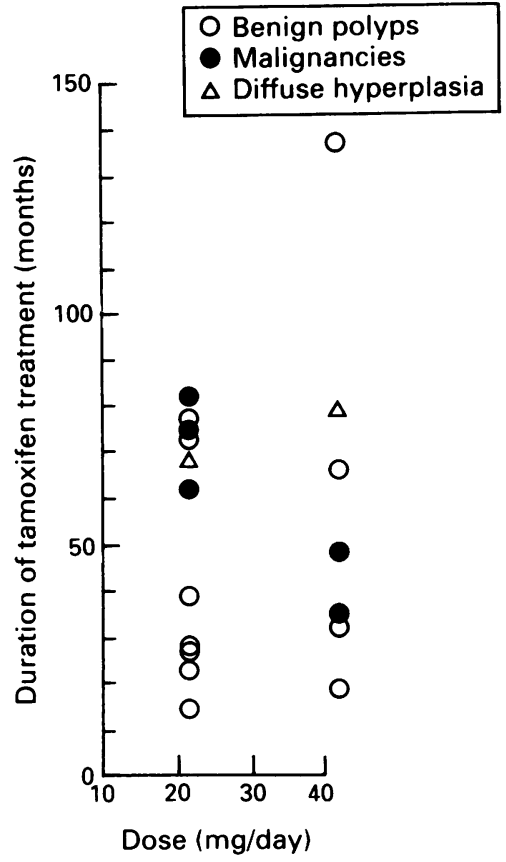

(A)

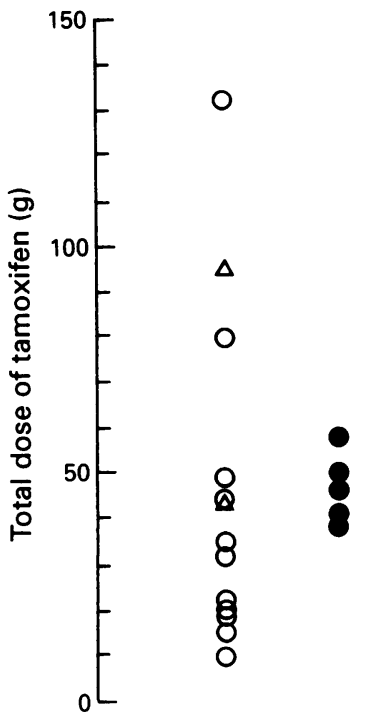

Endometrial pathology

Figure 6 Tamoxifen dose and type of endometrial pathology. (A) Daily dose and duration of treatment; $(B)$ cumulative dose of tamoxifen.

whom had received concurrent progestogen) provides pathological confirmation that tamoxifen promotes growth in the endometrium.

The development of endometrial malignancy may be promoted by the growth stimulating effect of the drug acting in concert with a genotoxic stimulus. Tamoxifen is a hepatic carcinogen in rats ${ }^{15}$ and has been shown to exert a dose dependent genotoxic effect on rat liver, ${ }^{16}{ }^{17}$ as well as in human lyphoblastoid cell lines. ${ }^{18}$ The possibility that it may have a genotoxic as well as a growth promoting effect on human endometrium cannot at present be ruled out.

Endometrial polyps, rare among the untreated controls, were an important feature of the uterus in women treated with tamoxifen. Many polyps were unusually large. In keeping with the growth promoting effect of the drug, the polyps occurred on a background of simple endometrial hyperplasia and were often multiple. Microscopically, the endometrial polyps seen in this series of treated uteri were distinguished from polyps of the usual type by the combination of proliferative activity, aberrant epithelial differentiation, and focal periglandular stromal condensation. The postulated oestrogen agonist activity of tamoxifen would account for the proliferative activity seen in these polyps. Similarly, epithelial metaplasias are a well documented finding in the endometria of women treated with oestrogens, ${ }^{19}$ and their occurrence in these uteri treated with tamoxifen could therefore be attributed to the oestrogen-like effect of tamoxifen.

The importance of the periglandular stromal condensation is uncertain, but this finding raised the possibility that these polyps may represent Müllerian adenosarcomas. How-

ever, the patchy nature of this stromal change, the relative paucity of mitotic activity, and absence of cytological atypia and atypical mitoses in the tamoxifen-associated polyps was thought to militate against a diagnosis of Müllerian adenosarcoma.

The occurrence of three endometrial polypcancers in this relatively small group of women treated with tamoxifen was unexpected as these lesions are otherwise extremely rare. Although no precise figures for incidence are available, only four polypcancers were noted in a study of 1100 endometrial polyps. ${ }^{20}$ The high prevalence of these rare lesions in this study population can only be explained by a sustained stimulus which favours the development of malignancy in endometrial polyps; the only candidate for this role, in this group of patients, is tamoxifen.

The polyp-cancers in this group of women occurred on a background of endometrial hyperplasia and multiple polyps showing a variable degree of atypical hyperplasia of their epithelial elements. These observations suggest that endometrial polypogenesis may form an important, perhaps essential, intermediate stage between simple endometrial hyperplasia and endometrial malignancy. I suggest that in susceptible patients simple endometrial hyperplasia is followed by endometrial polyps, atypical endometrial hyperplasia, and carcinoma. This proposed sequence of events agrees with the reported risk of subsequent endometrial carcinoma of $0.4-1 \%$ for simple endometrial hyperplasia, ${ }^{21} 22 \quad 3.5 \%$ for polyps, ${ }^{23}$ and $23 \%$ for atypical hyperplasia. ${ }^{22}$ The factors which influence an individual's susceptibility to this sequence of events are poorly understood. However, tamoxifen is clearly not the only important factor involved as, of the three women who received the highest cumulative dose of the drug, two had simple hyperplasia, one had multiple polyps, and none had a malignancy. An inherited predisposition to endometrial polyps or carcinoma, or both, may also be a factor.

The cancers in the present study were confined to women who had received a total tamoxifen dose in excess of $35 \mathrm{~g}$, irrespective of the daily dose of the drug. This observation suggests that the development of endometrial cancer in women treated with tamoxifen is related not to the daily dose of the drug but to the total dose taken, and that there is a threshold dose above which symptomatic patients have a high risk of an underlying endometrial carcinoma. The existence of this dose threshold, with the implication that women receiving the lower daily dose of the drug will develop endometrial carcinoma after a longer period of treatment, may explain the disparities in the reported incidence of endometrial carcinoma between the higher dose Stockholm trial ${ }^{10}$ and trials using the lower daily dose. ${ }^{24} 25$ If such a dose threshold is operative, an increase in the incidence of endometrial carcinoma among women receiving the lower daily dose would only become evident on follow up in excess of five years. 
The ongoing breast cancer prevention trials using long term tamoxifen in asymptomatic women have imparted urgency to the study of the endometrial effects of this drug. The findings of this small study support a link between tamoxifen and endometrial cancer and indicate that gynaecological symptoms in women treated with tamoxifen warrant full investigation. They suggest a pathogenetic relation between polypoid endometrial hyperplasia and malignancy and identify a subgroup of patients (those who have taken more than $35 \mathrm{~g}$ of tamoxifen) who may be at increased risk of harbouring endometrial cancer. It is recommended that tamoxifen registers be established to facilitate adequate follow up of women receiving prolonged tamoxifen treatment and to determine the incidence of endometrial pathology associated with the use of this drug.

I thank Professor Sir Dillwyn Williams and Dr Robert Newcombe for helpful discussions. Drs John Dinnen (County Hospital, Hereford), Gareth Melville-Jones (Withybush General Hospital), and Windsor Fortt (Royal Gwent Hospital) contributed the outside cases.

1 Furr BJA, Jordan VC. The pharmacology and clinical uses of tamoxifen. Pharmacol Ther 1984;25:127-205.

2 Baum M, Brinkley DM, Dosset JA, McPherson K, Jackson IM, Rubens RD, et al. Controlled trial of tamoxifen as a single adjuvant agent in management of early breast cancer. Br 7 Cancer 1988;57:608-11.

3 Nayfield SG, Karp JE, Ford LG, Dorr FA, Kramer BS. Potential role of tamoxifen in prevention of breast cancer. $7 N C I$ 1991;83:1450-9.

4 Powles TJ. The case for clinical trials of tamoxifen for prevention of breast cancer. Lancet 1992;340:1145-7.

5 Ferrazzi E, Cartei G, Mattarazzo R, Fiorentino M. Oestrogen-like effect of tamoxifen on vaginal epithelium. BrMed F 1977;1:1351-2.

6 Boccardo F, Bruzzi P, Rubagotti A, Nicolò G, Rosso R. Estrogen-like action of tamoxifen on vaginal epithelium of breast cancer patients. Oncology 1981;30:281-5.

7 Eells TP, Alpern HD, Grzywacz C, MacMillan RW, Olson JE. The effect of tamoxifen on cervical squamous maturation in Papanicolau stained cervical smears of postmenopausal women. Cytopathology 1990;1:263-8.

8 Boccardo F, Guarnieri D, Rubagotti A, Casertelli GL, Bentivoglio $G$, Conte $N$ et al. Endocrine effects of tamoxifen in postmenopausal breast cancer patients. Tumori 1984;70:61-8.

9 Lahti E, Blanco G, Kauppila A, Apala-Sarkkinen M, Taskinen PJ, Laatikainen T. Endometrial changes in postmenopausal breast cancer patients receiving tamoxifen. Obstet Gynecol 1993;81:660-4.

10 Fornander $T$, Rutqvist LE, Cedermark B, Glas V, Mattson A, Siltverswärd C, et al. Adjuvant tamoxifen in early breast cancer: occurrence of new primary tumours. Lancet 1989;i: 117-20.

11 Neven P, De Muylder X, Van Belle Y, Venderick G, De Muylder E. Tamoxifen and the uterus and endometrium. Lancet 1989;i:375.

12 Nuovo MA, Nuovo GJ, McCaffrey RM, Levine RU, Barron B, Winkler B. Endometrial polyps in postmenopausal patients receiving tamoxifen. Int $f$ Gynecol Pathol 1989;8:125-31.

13 Cross SS, Ismail SM. Endometrial hyperplasia in an oophorectomized woman receiving tamoxifen therapy. Case report. Br 7 Obstet Gynaecol 1990;97:551-2.

14 Corley D, Rowe J, Curtis MT, Hogan WM, Noumoff JS Livolsi VA. Postmenopausal bleeding from unusual endometrial polyps in women on chronic tamoxifen endometrial polyps in women on chro
therapy. Obstet Gynecol 1992;79:111-6.

15 Williams GM, Iatropoulos MJ, Djordjevic MV, Kaltenberg OP. The triphenylethylene drug tamoxifen is a strong liver carcinogen in the rat. Carcinogenesis 1993;13:315-7.

$16 \mathrm{Han}$ XH, Liehr JG. Induction of covalent DNA adducts in rodents by tamoxifen. Cancer Res 1992;52:1360-3.

17 White INH, De Matteis F, Davies A, et al. Genotoxic potential of tamoxifen and analogues in female Fischer F $344 / \mathrm{n}$ rats, DBA $/ 2$ and $\mathrm{C} 57 \mathrm{BL} / 6$ mice and in human MCL-5 cells. Carcinogenesis 1992;13:2197-203.

18 Styles JA, Davies A, Lim CK, De Matteis F, Stanley LA White INH, et al. Genotoxicity of tamoxifen, tamoxifen epoxide and toremifene in human lymphoblastoid cells epoxide and toremifene in human lymphoblastoid cells containing hur

19 Hendrickson MR, Kempson RL. Endometrial epithelia metaplasias: Proliferations frequently misdiagnosed as adenocarcinoma. Report of 89 cases and proposed classification. Am ₹ Surg Pathol 1980;4:525-42.

20 Peterson WF, Novak ER. Endometrial polyps. Obste Gynecol 1956;8:40-9.

21 McBride JM. Pre-menopausal cystic hyperplasia and endometrial carcinoma. $\mathcal{f}$ Obstet Gynaecol $\mathrm{Br}$ Emp 1959;66:288-96.

22 Kurman RJ, Kaminski PF, Norris HJ. The behavior of "undometrial hyperplasia. A long-term study of "untreated"

23 Armenia CS. Sequential relationship between endometrial polyps and carcinoma of the endometrium. Obstet Gynecol 1967;30:524-9.

24 Breast Cancer Trials Committee, Scottish Cancer Trials Office (MRC), Edinburgh. Adjuvant tamoxifen in the management of operable breast cancer: The Scottish Trial. Lancet 1987;ii:171-5.

25 Fisher B, Costantino J, Redmond C, Bowman D, Couture $\mathrm{J}$, Poisson $\mathrm{R}$, et al. A randomized clinical trial evaluating tamoxifen in the treatment of patients with node negative breast cancer who have estrogen-receptornegative breast cancer who have estrogen-receptor-
positive tumours. $N$ Engl $\mathcal{F}$ Med 1989;320: 479-84. 